\title{
Low-grade myofibroblastic sarcoma of the gingiva
}

\author{
L Montebugnoli, ${ }^{1}$ M Venturi, 1 D B Gissi,, ${ }^{1}$ Flamminio, ${ }^{2}$ M P Foschini² \\ ${ }^{1}$ Department of Oral Science, University of Bologna, Bologna, Italy \\ 2 Departments of Hematology and Oncology ‘L and A Seragnoli’, University of Bologna, Anatomic Pathology Bellaria Hospital, Bologna, Italy
}

Correspondence to L Montebugnoli, lucio.montebugnoli@unibo.it

\section{Summary}

Low-grade myofibroblastic sarcoma is a malignant tumour from myofibroblasts, which has only recently become clearly defined. It represents a rare entity developing in the soft tissues of the head and neck. About 20 cases have been reported in the oral cavity, especially in the tongue and bone, while gingiva as the primary site has been described only once to date. Diagnostic methods include histology and immunohistochemistry.

The present report concerns a case of a 37-year-old man who presented with a persistent gingival ulcerated swelling that was interpreted for a long time as a gingival epulis. A low-grade myofibrosarcoma was diagnosed and the patient underwent a segmental osteotomy of the mandibular symphisys for complete excision. There was no sign of recurrence or metastatic disease during the 18-month postoperative period.

\section{BACKGROUND}

This case report highlights the diagnostic features and clinical behaviour of an uncommon malignant neoplasm of the oral cavity.

\section{CASE PRESENTATION}

In September 2008, a 37-year-old man was referred to our department by his dentist because of a painful gingival lesion, with an 'ulcerative-desquamative look', persisting

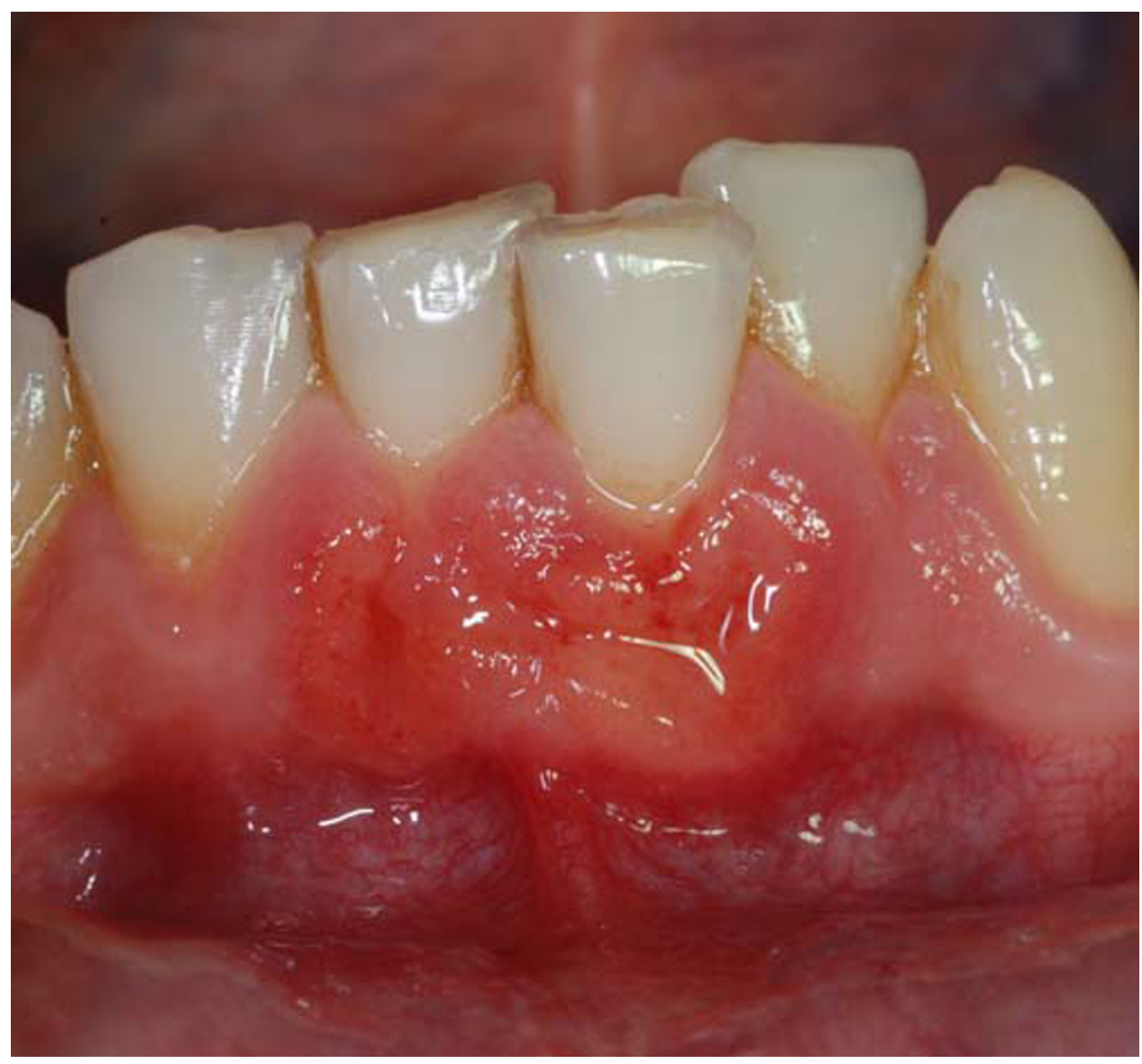

Figure 1 Physical examination showed a hard, lobulated, $2 \times 1.5 \mathrm{~cm}$ mass, fixed on the underlying tissues, with ulcerative fissures on the gingival surface. 


\section{BMJ Case Reports}
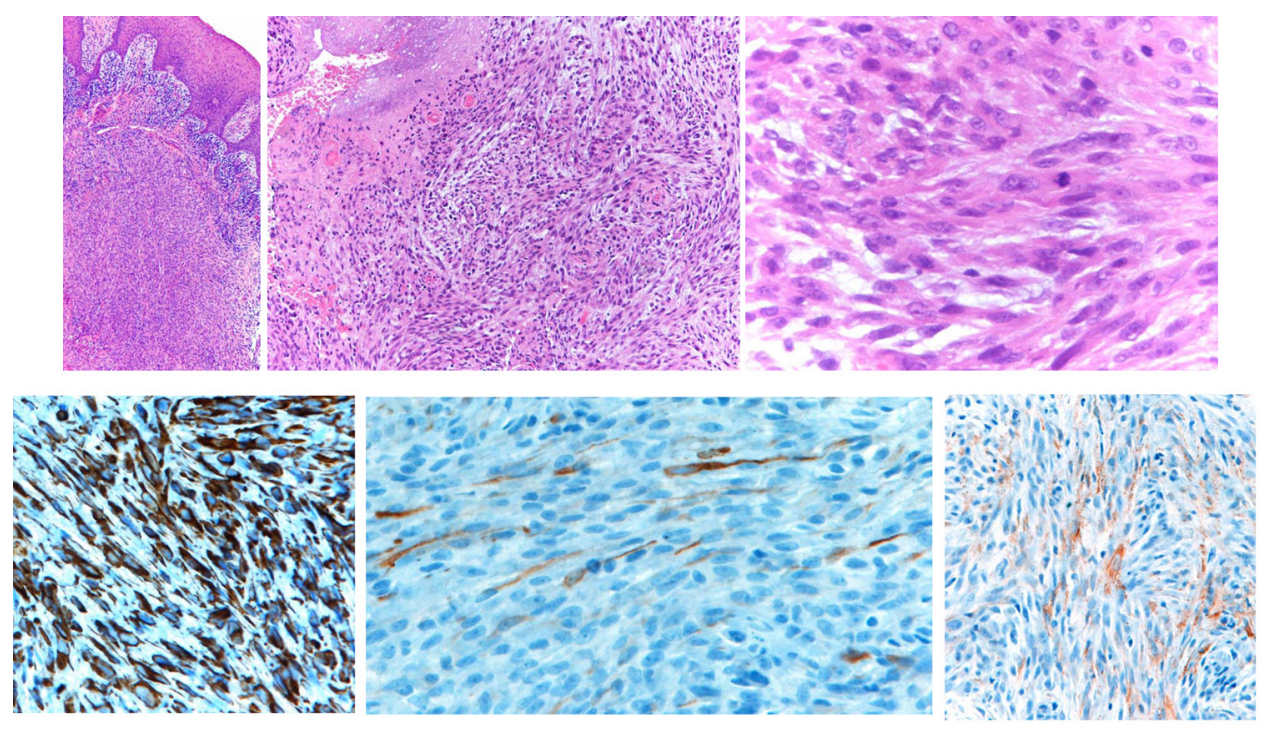

Figure 2 A. The neoplastic proliferation infiltrating the gingival chorion. B. At low power view the neoplastic cells were arranged in fascicles. Small areas of necrosis are visible at the upper left corner of the picture. C. At high power the neoplastic cells appear elongated, with atypical nuclei and evident nucleolus. D. Vimentin strongly stained all the neoplastic cells. Desmin $(\mathrm{E})$ and smooth muscle actin $(\mathrm{F})$ were focally positive.

for more than 3 months and not responding to periodontal and antibiotic treatments. The lesion was originally interpreted as a gingival epulis. Family and personal medical history revealed nothing meaningful. Physical examination showed a hard, lobulated, $2 \times 1.5 \mathrm{~cm}$ mass, fixed on the underlying tissues, with ulcerative fissures on the gingival surface (figure 1). No clinical evidence of lymphadenopathy was observed.

\section{INVESTIGATIONS}

Histologically, the lesion was composed of hypercellular areas. Neoplastic cells were spindle shaped and showed elongated, atypical nuclei with prominent nucleoli and eosinophilic cytoplasm. The cells were arranged in a diffusely infiltrative pattern within the gingival mucosa. The mitotic rate was of $3 / 10$ high power fields. Neoplastic cells were immersed in myxoid stroma. Focally, necrosis and calcifications were detected.

Immunohistochemically, the neoplastic cells were diffusely vimentin positive, focally smooth muscle actin and desmin positive. They were cytokeratin, CD34 and CD21 negative. Immunohistochemical staining showed intratumoural dendritic reticular cells, positive for S-100 protein. The overlying epithelium was ulcerated and showed acute and chronic inflammation (figure 2). The histological diagnosis was consistent with low-grade myofibrosarcoma. Orthopantomography and a CT scan showed no osteolytic activity. Positron emission tomography excluded a systemic spread of the neoplasm.

\section{DIFFERENTIAL DIAGNOSIS}

Low-grade myofibrosarcoma should be distinguished primarily from squamous oral cell carcinoma, the most common malignance of the oral cavity. Other less common conditions are nodular fascitiis, fibromatosis, myofibromatosis, other low-grade myofibroblastic sarcomas (infantile fibrosarcoma and inflammatory myofibrosarcoma), myopericytoma, fibrosarcoma, leiomyofibrosarcoma, solitary fibrous tumour and spindle cell carcinoma.

\section{TREATMENT}

The patient underwent surgical treatment consisting of a segmental osteotomy of the mandibular symphysis with loss of the lower incisors and contemporary removal of the overlaying buccal soft tissues. The lower canines and the basal part of the symphysis were conserved. Histological examination of the removed mass confirmed the diagnosis of myofibroblastic sarcoma and tumour-free resection margins (figure 3 ).

\section{OUTCOME AND FOLLOW-UP}

Since surgery, the patient has had a permanent hypoesthaesia to the lower lip. Presently, 18 months after surgery, radiological and clinical follow-up performed regularly every 6 months has not demonstrated signs of recurrence or metastatic disease.

\section{DISCUSSION}

Low-grade myofibroblastic sarcoma was recently described as representing a malignant mesenchymal tumour showing myofibroblastic differentiation.

It can occur at any age with a slight male predominance. About 20 cases have been reported in the oral cavity, especially in the tongue and bone, ${ }^{1}$ while gingiva as the primary site has been described only once so far. ${ }^{2}$

A painless, slow-growing mass with a relatively indolent course is the most common clinical presentation, ${ }^{13}$ and the frequent absence of a detectable epithelial discontinuity raises the risk of delay in diagnosis and subsequent worsening prognosis.

The correct diagnosis of myofibroblastic sarcomas can be challenging. At the clinical examination, the tumour mass 


\section{BMJ Case Reports}

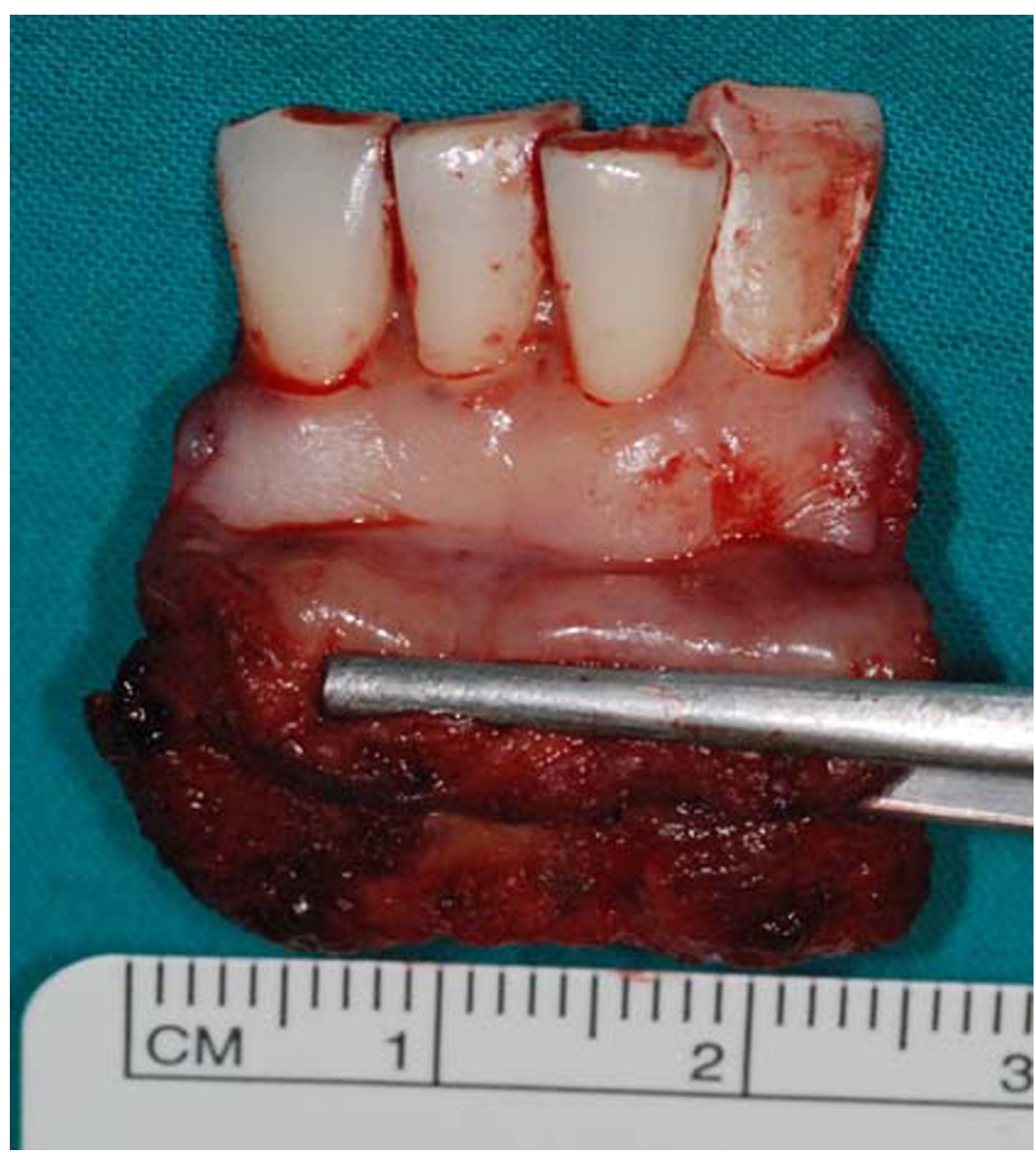

Figure 3 Surgical, free-margin excision of the myofibrosarcoma through segmental osteotomy of the mandibular symphysis with sacrifice of the lower incisors.

can be associated with a persisting ulceration as in the present case, but cases have been reported in the literature where the overlying mucosal surface appeared normal in colour and texture. ${ }^{4}$ Sometimes, diagnostic orientation can be confused by the anatomic location as in the present case, where an accumulation of plaque as a consequence of a poor oral hygiene might initially resemble common inflammatory periodontal disease.

The presence of an osteolytic and bone-destructive activity at Rx examination can address the diagnosis, ${ }^{4}$ although in our patient, where the tumour mass was so close to the bone, no bone involvement was demonstrated at the $\mathrm{Rx}$ examination.

A definitive diagnosis requires histopathological and immunohistochemical analyses. ${ }^{4}$ An incisional biopsy must be performed, reaching an adequate submucosal depth, because a misinterpretation can result from the specimen being sampled from the tumour surface, which contains mainly the granulation tissue-like and hypocellular areas but not the atypia hypercellular areas. ${ }^{5}$ Fine-needle aspiration biopsy might be non-contributory. ${ }^{6}$
Due to its rarity, the biological behaviour and the treatment of choice are still unclear. Aggressive surgical resection with wide margins and, occasionally, radiotherapy have been advocated. Although myofibrosarcomas generally behave as low-grade malignant sarcomas, sometimes they can exhibit an aggressive pattern with local recurrence, while distant metastases have been rarely reported. ${ }^{2} 37$ Consistent with the case reported here, evolving techniques of surgical reconstruction may allow more of these tumours to be completely resected, with less patient morbidity. ${ }^{8}$

\section{Learning points}

- Low-grade myofibroblastic sarcoma is an uncommon malignant neoplasm of the oral cavity.

- Diagnosis of low-grade myofibroblastic sarcoma can be challenging.

- Early detection of oral malignancies is based on histological examination of any suspect lesion. 


\section{BMJ Case Reports}

\section{Competing interests None.}

\section{Patient consent Obtained.}

\section{REFERENCES}

1. Jay A, Piper K, Farthing PM, et al. Low-grade myofibroblastic sarcoma of the tongue. Oral Surg Oral Med Oral Pathol Oral Radiol Endod 2007;104:e52-8.

2. Montgomery E, Goldblum JR, Fisher C. Myofibrosarcoma: a clinicopathologic study. Am J Surg Pathol 2001;25:219-28.

3. Mentzel T, Dry S, Katenkamp D, et al. Low-grade myofibroblastic sarcoma: analysis of 18 cases in the spectrum of myofibroblastic tumors. Am J Surg Pathol 1998;22:1228-38.
4. Demarosi F, Bay A, Moneghini L, et al. Low-grade myofibroblastic sarcoma of the oral cavity. Oral Surg Oral Med Oral Pathol Oral Radiol Endod 2009;108:248-54.

5. Meng GZ, Zhang HY, Bu H, et al. Myofibroblastic sarcoma of the nasal cavity and paranasal sinus: a clinicopathologic study of 6 cases and review of the literature. Oral Surg Oral Med Oral Pathol Oral Radiol Endod 2007:104:530-9.

6. Niedzielska I, Janic T, Mrowiec B. Low-grade myofibroblastic sarcoma of the mandible: a case report. J Med Case Reports 2009;3:8458.

7. Fisher C. Myofibrosarcoma. Virchows Arch 2004;445:215-23.

8. Keller C, Gibbs CN, Kelly SM, et al. Low-grade myofibrosarcoma of the head and neck: importance of surgical therapy. J Pediatr Hematol Oncol 2004:26:119-20.

This pdf has been created automatically from the final edited text and images.

Copyright 2010 BMJ Publishing Group. All rights reserved. For permission to reuse any of this content visit http://group.bmj.com/group/rights-licensing/permissions.

BMJ Case Report Fellows may re-use this article for personal use and teaching without any further permission.

Please cite this article as follows (you will need to access the article online to obtain the date of publication)

Montebugnoli L, Venturi M, Gissi DB, Flamminio F, Foschini MP. Low-grade myofibroblastic sarcoma of the gingiva. BMJ Case Reports 2010;

10.1136/bcr.07.2010.3166, date of publication

Become a Fellow of BMJ Case Reports today and you can:

- Submit as many cases as you like

Enjoy fast sympathetic peer review and rapid publication of accepted articles

Access all the published articles

Re-use any of the published material for personal use and teaching without further permission

For information on Institutional Fellowships contact consortiasales@bmjgroup.com

Visit casereports.bmj.com for more articles like this and to become a Fellow 